Original Article

\title{
PROSPECTIVE STUDY OF THE SIDE EFFECTS BETWEEN ATYPICAL-ATYPICAL ANTIPSYCHOTIC COMBINATIONS WITH TYPICAL-ATYPICAL ANTIPSYCHOTIC COMBINATIONS ON THE PSYCHOTIC DISORDERS INPATIENTS
}

\author{
CHILYATI EKY FUTIHAT ${ }^{1}$, ENDANG DARMAWAN ${ }^{*}$, ASTRIT IKAFITRIANI ${ }^{2}$
}

1Postgraduate Program of Clinical Pharmacy, Faculty of Pharmacy, Ahmad Dahlan University, Yogyakarta 55164, Indonesia, ${ }^{2} \mathrm{Hospital}$ Pharmacist, Grhasia Psychiatric Hospital Health Service DIY, Yogyakarta 55164, Indonesia Email: endang.darmawan@pharm.uad.ac.id

Received: 19 Jun 2020, Revised and Accepted: 15 Aug 2020

ABSTRACT

Objective: Antipsychotic therapy is the main therapy in psychotic disorders. Antipsychotics use often causes various side effects, such as the orthostatic hypotension, weight gain, and waist circumference. The study objective is to prove these side effects on combination therapy of atypicalatypical and typical-atypical antipsychotics on the psychotic disorders in patients.

Methods: This study method is a prospective cohort applied to psychotic disorders inpatients. This study is composed of 2 different groups(n=16). Data analysis using Risk Relative Ratio for orthostatic hypotension study variables and statistical difference test with $95 \%$ confidence level for study variables of weight gain and waist circumference.

Results: The $p$ value showed that there was no significant side effects of orthostatic hypotension $(p>0.05)$. Relative Risk Ratio (RR) value explained that the atypical-atypical antipsychotic combination group had opportunity to cause orthostatic hypotension side effects by 2,000 times greater than the typical-atypical antipsychotic combination group at $0^{\text {th }}$ week observation and 1,667 times greater than the typical-atypical antipsychotic combination group at $1^{\text {st }}$ and $2^{\text {nd }}$ week observations. Atypical-atypical antipsychotic combinations use and typical-atypical antipsychotic combinations use cause insignificant weight gain $(p>0.05)$. Typical-atypical antipsychotic combination use in the $2^{\text {nd }}$ week increases waist circumference greater than atypical-atypical antipsychotic combination use in the $2^{\text {nd }}$ week $(p<0.05)$.

Conclusion: Typical-atypical antipsychotic combinations use and atypical-atypical antipsychotic combination use did not cause significant on orthostatic hypotension and weight gain. Significant test results appear on the waist circumference increasing in the second week of typical-atypical antipsychotic combinations use when compared to atypical-atypical antipsychotic combinations use.

Keywords: Side Effects, Atypical, Typical, Psychotic Disorders

(C) 2020 The Authors. Published by Innovare Academic Sciences Pvt Ltd. This is an open access article under the CC BY license (http://creativecommons.org/licenses/by/4.0/) DOI: http://dx.doi.org/10.22159/ijcpr.2020v12i5.39764. Journal homepage: https://innovareacademics.in/journals/index.php/ijcpr

\section{INTRODUCTION}

Psychotic is a psychiatric disorder characterized by symptoms such as delusions, hallucinations, irregular thoughts and abnormal motor behavior [1]. Psychotic disorders consist of schizophrenia and mood disorders [2]. Schizophrenia is a complex psychiatric disorder. This psychiatric disorder is a heterogeneous syndrome where the mind is irregular and strange, delusional, hallucinatory, and impaired cognitive abilities [3]. According to WHO data (2016), schizophrenia affects about 21 million people. According to Riskesdas data (2013) the prevalence of schizophrenia in Indonesia reaches around 400,000 people or $1.7 / 1,000$ population [4].

Antipsychotics use must consider its benefits and its side effects because it determines the success of therapy. Orthostatic hypotension is one of its side effects. Occurence rate of orthostatic hypotension depends on the level of $\alpha 1$-adrenoceptor antagonists. Clozapin and Risperidon are on high occurrence rates [5]. Typical antipsychotics use, such as haloperidol, has a weaker potential to cause orthostatic hypotension than clozapin or risperidone [6]

Weight gain is a common side effect of antipsychotics use, especially on the clozapine use [6]. Another study states that clozapin has a higher potential for weight gain than risperidone and haloperidol [7]. Determination of obesity based on body mass index calculation (BMI) [8].

Excess of fat accumulation in the stomach is closely related to the risk of cardiovascular disease. The easiest way to diagnose obesity is to measure waist circumference. The greatest increase of waist circumference occurs in atypical antipsychotics use, specifically clozapin. Only the chlorpromazine group increases waist circumference in first-generation antipsychotics [8]. Other study states that there is no significant difference in the increase of waist circumference using risperidone and placebo [9].

\section{MATERIALS AND METHODS}

\section{Study design and setting}

This study is an observational study with a cohort design. This study collected prospectively data for 1 mo of observation through medical records and direct examination of subjects. This data can show the side effects on combination therapy of atypical-atypical and typical-atypical antipsychotics on the psychotic disorders inpatients in Grhasia Mental Government Hospital of Yogyakarta of Indonesia.

\section{Sample size and sampling methods}

43 subjects were the subject of this study based on inclusion criteria. This study excluded 11 samples from time to time, then divided the remaining 32 subjects into two combination groups: 16 subjects in the atypical-atypical antipsychotic combination group and as many as 16 subjects in the typical-atypical antipsychotic combination group. The inclusion criteria were inpatients diagnosed with psychotic disorders by doctors and aged 15-65 y, who were willing to take part in the study with inform consent. Fig. 1 explains the study procedure.

Data collection

This study took medical record data on subjects with inclusion criteria, then the researchers measured blood pressure, weight, height and waist circumference every week for 1 mo of observation time and/or period during the subjects hospitalized. 


\section{Instrument}

Patient medical record data contained sociodemographic data of the subjectssuch as the subject's age, gender, diagnosis, employment status and education level. This study measured observational data including orthostatic blood pressure (The American Academy of Neurology and the Joint Consensus Committee of the American Autonomic Society, 1996) [10], BMI(WHO, 1995) [11], and waist circumference $(I D F, 2006)[12]$. Since the subjects transfer from the intensive unit to the care unit until doctor sent the patient home and/or for 1 mo of observation.

\section{Ethical approval}

Health Research Ethics Commission Grhasia Mental Government Hospital of Yogyakarta of Indonesia has approved this study based on letter number 07/EC-KEPKRSJG/VII/2019.

\section{Data analysis}

This study analyzes data in a univariate and bivariate method. Determination of sociodemographic frequency distribution of psychotic disorders subjects using univariate analysis. This study uses bivariate analysis to determine whether there are differences between types of therapy (independent variables) on side effects (dependent variable) such as orthostatic hypotension, weight gain and increased waist circumference. The Relative Risk Ratio (RR) analysis in this study uses a $95 \%$ confidence level to determine the strength of the effect of antipsychotic combinations use (exposure) to the risk of side effects of orthostatic hypotension (outcome) between the two groups of antipsychotic combinations. Weight gain and waist circumference variable using statistical analysis of different tests. The analysis is independent sample t-test for parametric or normally distributed data, and Mann Whitney test for non-parametric or non-normally distributed data.

\section{RESULTS AND DISCUSSION}

\section{Socio-demographic characteristics of subjects}

The sample consisted of 32 subjects, the samples were inpatients with psychotic disorders and matched the inclusion criteria. Most subjects were $<40$ y $(68 \%)$, most subjects were also men $(71.9 \%)$, and most subjects also had a diagnosis of F. 20 or schizophrenia $(81.2 \%)$ based on descriptive statistical analysis Univariate sociodemographic characteristics of subjects in table 1. Most subjects have homelessness employment status (78.1\%) and with high school education level (71.9\%). Table 1 shows the results of the descriptive statistical analysis of the socio-demographic characteristics of the subjects.

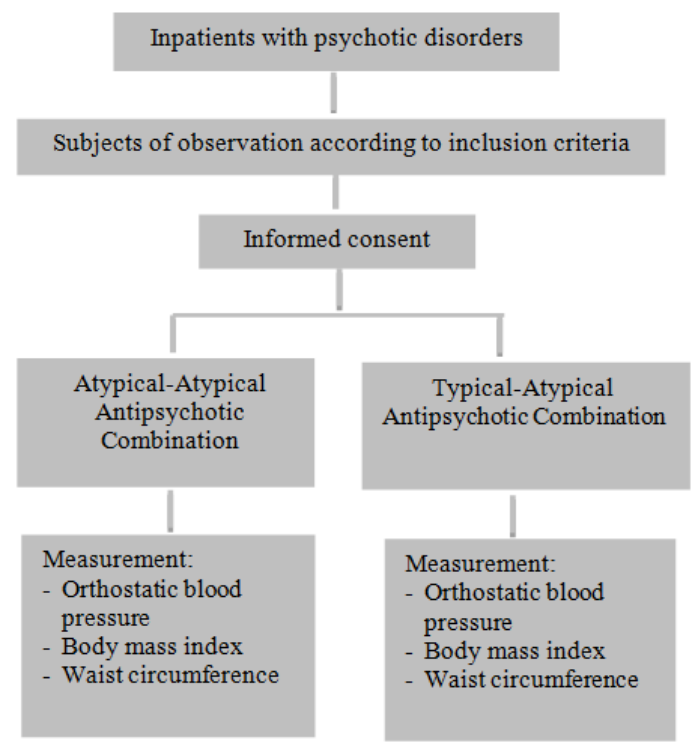

Fig. 1: Study prosedure

Men have the onset of schizophrenia at the age of 18-25 $y$, whereas in women, the onset at the age of 25-35 y [13]. Schizophrenia most often occurs in productive age, namely early adulthood to under $40 \mathrm{y}$ of age. This is due to stress factors, family responsibilities, and economic problems to workloads that affect emotional development [14]. This is consistent with the results of this study, where most subjects were in the age range $<40 \mathrm{y}$.

Table 1: Demographic characteristics of subjects

\begin{tabular}{ll}
\hline Characteristics subject $\mathbf{n}=\mathbf{3 2}$ & Frequency, total \\
\hline Age, $n$ (\%) & $22(68,8 \%)$ \\
$<40$ y old & $10(31,2 \%)$ \\
$\geq 40$ y old & \\
Gender, $n$ (\%) & $23(71,9 \%)$ \\
Male & $9(28,1 \%)$ \\
Female & \\
Diagnosis, $n$ (\%) & $26(81,2 \%)$ \\
F. 20 & $3(9,4 \%)$ \\
F. 25 & $2(6,2 \%)$ \\
F. 31 & $1(3,1 \%)$ \\
F. 32 & $7(21,9 \%)$ \\
Employment status, $n(\%)$ & $25(78,1 \%)$ \\
Work & $1(3,1 \%)$ \\
Homelessness & $4(12,5 \%)$ \\
Education Level, $n(\%)$ & $3(9,4 \%)$ \\
No School & $23(71,9 \%)$ \\
Elementary School & $1(3,1 \%)$ \\
Junior High School & \\
Senior High School & \\
College &
\end{tabular}

Schizophrenia cases are more detectable in men compared to women [13]. This is consistent with the results of this study, where more male subjects, especially with the diagnosis of schizophrenia. Women are associated with the influence of estrogen, which can reduce sensitivity to the D2 receptor, which looks like an antipsychotic effect. Therefore women tend to experience a decline in onset and a better course of schizophrenia [15]. Psychotic disorders affect one's ability to live the necessities of life, one of which is the risk of being homeless with an annual prevalence of 5\% [1]. Most patients have difficulty working, looks at the number of homeless subjects in the study result. 
The most common pattern of antipsychotic use is combination antipsychotic therapy. The most frequent use of atypical-atypical antipsychotic combination is Clozapine-Risperidone $(87,5 \%)$. While the most frequent use of typical-atypical antipsychotic combinationis Clozapine-Risperidone-Haloperidol (56,25\%). The pattern of antipsychotic combination as shown in table 2 .

Table 2: Data patterns on the use of antipsychotic combinations in inpatients

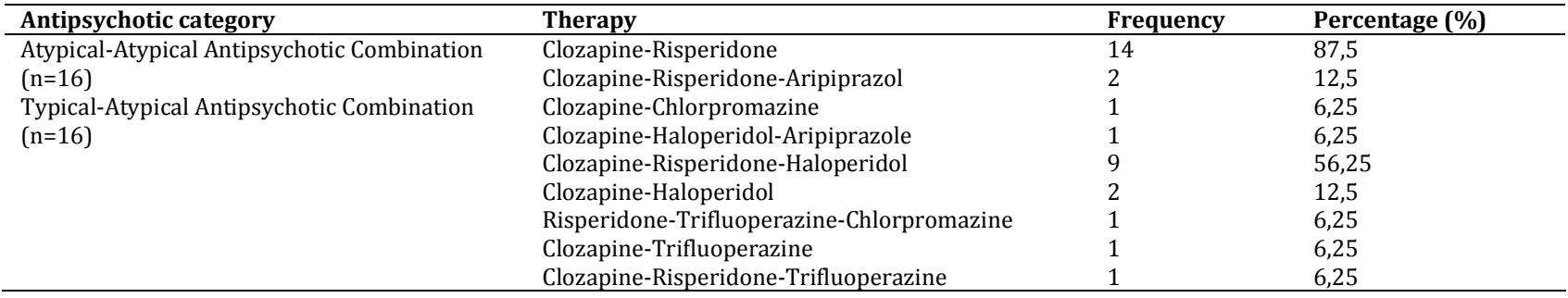

Table 3: Profile of the number of subjects who experienced orthostatic hypotension in each treatment group

\begin{tabular}{|c|c|c|c|c|c|c|c|}
\hline \multicolumn{2}{|c|}{ Treatment Group } & \multicolumn{2}{|l|}{ Side Effect } & \multicolumn{4}{|c|}{ Outcome } \\
\hline & & \multirow[t]{2}{*}{$\mathrm{OH} \mathrm{(+)}$} & \multirow[t]{2}{*}{ OH (-) } & \multirow[t]{2}{*}{ RR } & \multirow[t]{2}{*}{$p$ value } & \multicolumn{2}{|l|}{ CI95\% } \\
\hline & & & & & & lower & upper \\
\hline \multirow[t]{2}{*}{$0^{\text {th }}$ Week } & A-A & $8(50 \%)$ & $8(50 \%)$ & 2,000 & 0,273 & 0,751 & 5,329 \\
\hline & T-A & $4(25 \%)$ & $12(75 \%)$ & & & & \\
\hline \multirow[t]{2}{*}{$1^{\text {st }}$ Week } & A-A & $5(31,2 \%)$ & $11(68,8 \%)$ & 1,667 & 0,685 & 0,476 & 5,831 \\
\hline & T-A & $3(18,8 \%)$ & $13(81,2 \%)$ & & & & \\
\hline \multirow[t]{2}{*}{$2^{\text {nd }}$ Week } & A-A & $5(31,2 \%)$ & $11(68,8 \%)$ & 1,667 & 0,685 & 0,476 & 5,831 \\
\hline & T-A & $3(18,8 \%)$ & $13(81,2 \%)$ & & & & \\
\hline
\end{tabular}

Note: A-A = Atypical-Atypical Antipsychotic Combination; T-A = Typical-Atypical Antipsychotic Combination; OH $(+)=$ Experience orthostatic hypotension; $\mathrm{OH}(-)=$ Do not experience orthostatic hypotension

\section{Effects of antipsychotic combinations on the side effect of} orthostatic hypotension

In table 3, it appears that the use of antipsychotics does not have a major effect on the side effects of orthostatic hypotension. In the atypical-atypical antipsychotic combination and the typical-atypical antipsychotic combination group decreased the number of subjects experiencing the side effect of orthostatic hypotension. The $p$ value explained there was no significant relationship between the use of antipsychotic combinations with the incidence of orthostatic hypotension side effects $(p>0,05)$. Relative Risk Ratio (RR) value explained that the atypical-atypical antipsychotic combination grouphad the opportunity to cause orthostatic hypotension side effects by 2,000 times greater than the typical-atypical antipsychotic combination group at $0^{\text {th }}$ week observations and 1,667 times greater than the typical-atypical antipsychotic combination group at $1^{\text {st }}$ and $2^{\text {th }}$ week observations.

In elderly patients, the prevalence of orthostatic hypotension increases to $10-30 \%$. This is due to impaired baroreflex sensitivity, volume status, and venomotor tone [16]. In other literature, the prevalence of orthostatic hypotension depends on age, ranging from $5 \%$ in patients $<50 \mathrm{y}, 20 \%$ in patients aged $65 \mathrm{y}$, and $30 \%$ in patients $>70 \mathrm{Y}[17,18]$. This study shows the age of the subjects in the range of 24 to $55 \mathrm{y}$ and the age of most subjects at the age of $<40$ $y(68.8 \%)$, so that the side effects of orthostatic hypotension are not seen in all subjects.

In addition, antipsychotics, especially clozapine can cause side effects of orthostatic hypotension in about $9 \%$ of patients and usually occur earlyin treatment and are usually temporary. Although patients can usually tolerate it in 4 to $6 \mathrm{w}$, hypotension can persist in some patients. The patient may experience dizziness or mild headaches to syncope [19]. In this study, subjects first underwent intensive unit about $1 \mathrm{w}$ and then observation began after the patient underwent a recovery period in the care unit for $3 \mathrm{w}$ of observation. During the observation period the side effects of orthostatic hypotension were not seen in all subjects, this is consistent with the statement above where the side effects of orthostatic hypotension occur around $9 \%$ at the start of treatment and patients can tolerate it in 4 to $6 \mathrm{w}$.
Effects of antipsychotic combinations on the side effect of weight gain

Body mass index measurements at $0^{\text {th }}$ week, $1^{\text {st }}$ week and $2^{\text {nd }}$ week. The average body mass index of the atypical-atypical antipsychotic combination group at $0^{\text {th }}$ week, $1^{\text {st }}$ week and $2^{\text {nd }}$ week in the normal range is $23,93 \pm 5,03 \mathrm{~kg} / \mathrm{m}^{2}, 24,13 \pm 4,77 \mathrm{~kg} / \mathrm{m}^{2}, 24,29 \pm 4,57 \mathrm{~kg} / \mathrm{m}^{2}$. The average body mass index of the typical-atypical antipsychotic combination group at $0^{\text {th }}$ week, $1^{\text {st }}$ week and $2^{\text {nd }}$ week also in the normal range is $23,10 \pm 2,89 \mathrm{~kg} / \mathrm{m}^{2}, 23,20 \pm 2,78 \mathrm{~kg} / \mathrm{m}^{2}, 23,37 \pm 2,82 \mathrm{~kg} / \mathrm{m}^{2}$.

Determine the difference in the average body mass index of the atypical-atypical antipsychotic combination group and the typicalatypical antipsychotic combination group with parametric analysis of the independent sample $t$-test, and because of the lack of normality distribution $(\mathrm{p}<0.05)$, analysis was also performed using tests MannWhitney Utest. Table 4 shows that in the atypical-atypical antipsychotic combination group an average increase in body mass index was greater than the typical-atypical antipsychotic combination group, but did not cause a significant increase $(p>0.05)$ in either the first week or the second week of observation.

People with mental disorders, including psychotic disorders, have a greater tendency to experience increased body mass. The tendency of weight gain in patients with psychotic disorders is influenced by several factors, including special diet and lifestyle as well as the effects of some antipsychotic drugs that cause an increase in body mass [8]. Increased body mass is associated with impaired satiety/appetite control, metabolic disorders and a less active lifestyle $[8,20]$. Obesity can affect mental function by changing brain plasticity, which contributes to the development of cognitive and mood disorders. In addition to the above factors, there is a genetic predisposition for patients with mental disorders to excessive accumulation of body fat [8]. Genetic polymorphisms can explain individual variations in weight gain due to the use of antipsychotics. A recent meta-analysis identified 13 single nucleotide polymorphisms from nine genes that were significantly associated with weight gain due to antipsychotic use. The single nucleotide polymorphism associated with the ADRA2A, DRD2, 5-HTR2C and MC4R genes shows the greatest effect [21]. 
The effect of antipsychotic use on increasing body mass varies. The greatest increase in body mass after the use of new generation atypical antipsychotics, especially like clozapine and olanzapine [8, $20,22]$. Atypical antipsychotics that do not cause an increase in body mass are molindone, ziprasidone, and aripiprazole. While the typical antipsychotic that causes an increase in body mass is only chlorpromazine [8].

Weight gain increases rapidly in the initial period after starting antipsychotic use and lasts long term [20]. Weight gain due to atypical and typical antipsychotics can occur after standard-dose therapy for $10 \mathrm{w}$. Patients who received placebo experienced weight loss, while those who received antipsychotics experienced weight gain. Antipsychotics that cause weight gain are clozapine, chlorpromazine and risperidone [20]. Patients with first-episode psychotic disorders also reported a weight gain of $3.22 \mathrm{~kg}$ in the short term $(\leq 12 \mathrm{w})$ and $5.3 \mathrm{~kg}$ in the long term $(>12 \mathrm{w})$ compared with placebo [23]. Factors associated with rapid weight gain in the early period are younger age, lower initial body mass index (BMI), stronger responses to antipsychotics and increased appetite.

Table 4: Body mass index profile of subjects using atypical-atypical antipsychotics combination vs typical-atypical antipsychotic combination

\begin{tabular}{lll}
\hline Difference of body mass index & IMT $\left(\mathbf{k g} / \mathbf{m}^{2}\right)$ & \\
\cline { 2 - 3 } & $\begin{array}{l}\text { Atypical-atypical antipsychotic combination } \\
(\mathbf{n = 1 6 )}\end{array}$ & $\begin{array}{l}\text { Typical-atypical antipsychotic } \\
\text { combination (n=16) }\end{array}$ \\
\hline Difference at $0^{\text {th }}$ Week and $1^{\text {st }}$ Week & $0,19 \pm 0,48$ & $0,10 \pm 0,26$ \\
Difference at $0^{\text {th }}$ Week and $2^{\text {nd }}$ Week & $0,36 \pm 0,72$ & $0,27 \pm 0,50$ \\
\hline
\end{tabular}

Mann WhitneyTest: significant if $\mathrm{p}<0,05$, Independent Sample T-Test: significant if $\mathrm{p}<0,05$

Rapid weight gain of more than $5 \%$ in the first month is the best predictor of significant long-term weight gain [24].

Receptors that cause weight gain due to antipsychotic use are serotonin 5-HT2A, serotonin 5-HT2C, dopamine D2, dopamine D3, histamine $\mathrm{H} 1$ and M3 muscarinic receptors [20]. Lopuszanska (2017) reported that patients who received typical-atypical antipsychotic combination therapy had a tendency to increase body mass that was not significant compared to patients who did not get the antipsychotic combination [8]. This is consistent with the results of this study, that antipsychotic combination use does not cause significant weight gain $(p>0,05)$. It is also associated with food intake according to nutrition calculations by nutritionists. Patients with normal weight get 3 main meals and 1 additional food with a total calorie of 2400 calories Activities during inpatient also controlled and scheduled every day.

Effects of antipsychotic combinations on the side effect of increased waist circumference

Waist Circumference measurements at $0^{\text {th }}$ week, $1^{\text {st }}$ week and $2^{\text {nd }}$ week. The average waist circumference of the atypical-atypical antipsychotic combination group at $0^{\text {th }}$ week, $1^{\text {st }}$ week and $2^{\text {nd }}$ week is $87,01 \pm 10,69 \mathrm{~cm} ; 87,36 \pm 10,41 \mathrm{~cm} ; 87,67 \pm 10,11 \mathrm{~cm}$. The average waist circumference of the typical-atypical antipsychotic combination group at $0^{\text {th }}$ week, $1^{\text {st }}$ week and $2^{\text {nd }}$ week also is $84,78 \pm 8,51 \mathrm{~cm} ; 85,44 \pm 8,56 \mathrm{~cm} ; 86,31 \pm 8,42 \mathrm{~cm}$. Based on IDF guidelines, there were 11 subjects (34.37\%) diagnosed with abdominal obesity. Atypical-atypical antipsychotic group occurred in 6 female subjects (37.5\%). Whereas in the typical-atypical antipsychotic group occurred in 5 subjects $(31.25 \%)$, which occurred in 3 male subjects and 2 female subjects.
Table 5 shows that an average increase in waist circumference in the first week of the typical-atypical antipsychotic combination group was greater than the atypical-atypical antipsychotic combination group but did not cause a significant $(p>0.05)$. Whereas in the second week, the average waist circumference increased significantly $(\mathrm{p}<0,05)$.

Determine the difference in the average waist circumference of the atypical-atypical antipsychotic combination group and the typicalatypical antipsychotic combination group with non-parametric analysis of the Mann-Whitney $U$ test because of the lack of normality distribution $(\mathrm{p}<0.05)$

Patients with mental disorders, especially schizophrenia, schizoaffective disorders, mood disorders, single and bipolar disorders, have a greater tendency to store fat tissue in the abdominal area, and this tendency increase with antipsychotics use [8]. The use of secondgeneration antipsychotics especially clozapin and risperidone can cause weight gain and the risk of metabolic syndrome. therefore, it is important to monitor waist circumference initially and regularly[25, 26]. Other studies report a significant increase in waist circumference in the use of chlorpromazine, risperidone and haloperidol after $12 \mathrm{w}$ compared to baseline measurements [27].

The results of this study report that increase in waist circumference the typical-atypical antipsychotic combination group was greater than the atypical-atypical antipsychotic combination group in the second week. This is because subjects who receive typical-atypical antipsychotic combination therapy, get two even more antipsychotic combinations, thereby causing greater side effects.

Table 5: Waist circumference profile of subjects using atypical-atypical antipsychotics combination vs typical-atypical antipsychotic combination

\begin{tabular}{lll}
\hline Difference of waist circumference & Waist circumference (cm) & \\
\cline { 2 - 3 } & $\begin{array}{l}\text { Atypical-atypical antipsychotic } \\
\text { combination }(\mathbf{n = 1 6 )}\end{array}$ & $\begin{array}{l}\text { Typical-atypical antipsychotic } \\
\text { combination (n=16) }\end{array}$ \\
\hline Difference at $0^{\text {th }}$ Week and $1^{\text {st }}$ Week & $0,35 \pm 0,53$ & $0,66 \pm 1,08$ \\
Difference at $0^{\text {th }}$ Week and $2^{\text {nd }}$ Week & $0,66 \pm 0,99$ & $1,53 \pm 1,26$ \\
\hline
\end{tabular}

Mann Whitney test: ${ }^{*}$ significant if $\mathrm{p}<0,05$

\section{CONCLUSION}

Subjects who use atypical-atypical antipsychotic combinations or typical-atypical antipsychotic combinations experience insignificant side effects of orthostatic hypotension and weight gain. While a significant increase in waist circumference occurred in the typical-atypical antipsychotic combination group compared to the atypical-atypical antipsychotic combination group at the second week of observation.

\section{ACKNOWLEDGEMENT}

The authors are grateful to the hospital director, head of pharmaceutical installation, chief of medicine ward, ward nurse, for their assistance and cooperation throughout the study. The authors would like to thank the research subjects, namely, psychotic disorders inpatients on mental hospitals in Yogyakarta of Indonesia. 


\section{FUNDING}

$\mathrm{Nil}$

\section{AUTHORS CONTRIBUTIONS}

All the author has contributed equally.

\section{CONFLICT OF INTERESTS}

\section{Declared none}

\section{REFERENCES}

1. Lieberman JA, First MB. Psychotic disorders. N Engl J Med 2018;379:270-80.

2. R Maslim. Pocket book diagnosis for mental disorders. Brief reference from practical guidelines for diagnosing mental disorders-III and the diagnostic and statistical manual of mental disorders (DSM-5); 2013.

3. Mueser KT, Jeste DV. Clinical handbook of schizophrenia; 2008.

4. Fidiansyah. The Role of the Family Supports Community Mental Health; 2016.

5. Haddad PM, Sharma SG. Adverse effects of atypical antipsychotics differential risk and clinical implications. CNS Drugs 2007;21:911-36.

6. Gardner DM, Baldessarini RJ, Waraich P. Modern antipsychotic drugs: a critical overview; 2005. p. 172.

7. Keks NA. Are atypical antipsychotics advantageous? The case against. Aust Prescr 2004;27:149-51.

8. Lopuszanska U, Makara Studzinska M. Relationship between antipsychotic medication, obesity and cognitive functions. Curr Probl Psychiatry 2017;18:272-8.

9. Honer WG. Clozapine alone versus clozapine and risperidone with refractory schizophrenia. N Engl J Med 2006:354:472-82.

10. The consensus committee of the american autonomic society and the american academy of neurology. Consensus statement on the definition of orthostatic hypotension, pure autonomic failure, and multiple system atrophy. Neurology 1996;46:1470.

11. WHO. Physical Status: The Use and Interpretation of Anthropometry: Report of a World Health Organization (WHO) Expert Committee; 1995.

12. International Diabetes Federation. The IDF Consensus Worldwide Definition of the Metabolic Syndrom. IDF; 2006.

13. Labad X, Kulkarni J, Ochoa S, Usall J. Gender differences in schizophrenia and first-episode psychosis: a gender differences in schizophrenia and first-episode psychosis; 2012.
14. MD Yulianty, N Cahaya, VM Srikartika. Study of antipsychotic use and side effects in schizophrenia patients at sambang lihum mental hospital in south kalimantan. J Sains Farm Klin 2017;3:153.

15. Hafner H. Gender differences in schizophrenia Psychoneuroendocrinology 2003;28:17-54.

16. Low PA, Tomalia VA. Orthostatic hypotension: mechanisms, causes, management. J Clin Neurol 2015;11:220-6.

17. Ricci F, Caterina R De, Fedorowski A. Orthostatic hypotension. J Am Coll Cardiol 2015;66:848-60.

18. Gupta V, Lipsitz LA. Orthostatic hypotension in the elderly: diagnosis and treatment. Am J Med 2007;120:841-7.

19. Krakowski M, Czobor $\mathrm{P}$, Citrome L. Weight gain, metabolic parameters, and the impact of race in aggressive inpatients randomized to double-blind clozapine, olanzapine or haloperidol. Schizophr Res 2009;110:95-102.

20. Dayabandara M. Antipsychotic-associated weight gain: management strategies and impact on treatment adherence. Neuropsychiatr Dis Treat 2017;13:2231-41.

21. Zhang J. Pharmacogenetic associations of antipsychotic drugrelated weight gain: a systematic review and meta-analysis. Schizophr Bull 2016;42:1418-37.

22. Muench J, Hamer AM. Adverse effects of antipsychotic medications. Am Fam Physician 2010;81:617-22.

23. Tek C. Antipsychotic-induced weight gain in first-episode psychosis patients: a meta-analysis of differential effects of antipsychotic medications. Early Interv Psychiatry 2016;10:193-202.

24. Vandenberghe F. Importance of early weight changes to predict long-term weight gain during psychotropic drug treatment. J Clin Psychiatry 2015;76:1417-23.

25. Citrome L, McEvoy JP, Saklad SR. A guide to the management of clozapine-related tolerability and safety concerns. Clin Schizophr Relat Psychoses 2016;10:163-77.

26. Henderson DC. Waist circumference is the best anthropometric predictor for insulin resistance in nondiabetic patients with schizophrenia treated with clozapine but not olanzapine. Int J Psychiatry Clin Pract 2009; 15:251-61.

27. Mulat E, Mossie A, Negash A, Ibrahim M. Effect of antipsychotic drugs on body composition in patients attending psychiatry clinic, jimma, Ethiopia. J Psychiatry 2017;20:1-7. 